\section{Diagnostic Utility of Anticarbamylated Protein Antibodies as Measured Using Carbamylated Fetal Calf Serum}

\section{To the Editor:}

Rheumatoid factor (RF) and anticitrullinated protein antibodies (ACPA) are important biomarkers in the diagnosis of rheumatoid arthritis (RA), but leave a gap of about $30-50 \%$ seronegative RA, which drives the demand for novel biomarkers. In 2011 a novel autoantibody system, anticarbamylated protein (anti-CarP) antibodies, was described in the sera of patients with $\mathrm{RA}^{1}$. In contrast to enzyme-mediated protein citrullination, carbamylation is a chemical reaction whereby cyanate converts lysine into homocitrulline ${ }^{1}$, a protein modification that is chemically similar to citrulline (1 $\mathrm{CH} 2$ longer side chain $)^{2}$. Most studies on anti-CarP antibodies have used an ELISA based on carbamylated fetal calf serum (Ca-FCS) and accordingly a complex mixture of carbamylated proteins as the antigen $(s)^{1,2}$. Although many clinical observations have been reported, precise information on the antigenic targets of anti-CarP antibodies is limited. Importantly, anti-CarP antibodies have been detected in both ACPA-positive and ACPA-negative RA patients, suggesting that they might represent an important test in the diagnosis of $\mathrm{RA}^{1,2}$. A recent metaanalysis estimated the sensitivity, specificity, and OR of anti-CarP antibodies as $42 \%$ (95\% CI 38-45), 96\% (95\% CI 95-97), and 17 (95\% CI 12-24), respectively, when comparing RA to healthy controls ${ }^{3}$. It was also demonstrated that anti-CarP antibodies predict joint damage as assessed by total Sharp/van der Heijde score in a large cohort of sequential RA samples ${ }^{1,2}$. Additionally, anti-CarP antibodies were reported to be useful in predicting the future development of RA in patients presenting with arthralgia, in first-degree relatives of patients with RA, and even in apparently healthy individuals ${ }^{2}$. Besides the potential utility in the diagnosis of RA, one of the main benefits of anti-CarP antibodies is the reported strong association with joint erosions and more rapid radiographic progression of disease ${ }^{1,2}$. Even though anti-CarP antibodies are predominantly found in patients with RA, they are also found in other inflammatory conditions, albeit at considerably lower frequencies ${ }^{4}$, which certainly brings into question the diagnostic specificity.

In this context, we read with interest the recent paper by Nakabo, et $a l^{5}$ on the diagnostic utility of anti-CarP antibodies. The authors studied anti-CarP antibodies in 265 patients with RA [ 209 cyclic citrullinated peptide (CCP)-positive and $56 \mathrm{CCP}$-negative] and 616 controls (mostly connective tissue disease) using an ELISA following the original method and protocol with Ca-FCS, as published by Shi, et $a l^{2}$. Based on the results of the study, the authors concluded that anti-CarP antibodies are not useful in the diagnosis of RA. Unfortunately, no commutability data between the method used in this study and the original method (e.g., by interlaboratory sample exchange) was presented. In addition, there was deviation from the original protocol (e.g., sample dilution) and lack of protocol details (e.g., incubation time and reaction conditions). It should also be clarified that the pre-test probability does not affect the sensitivity and specificity of a given test, as stated by the authors. In contrast, the composition of the control group has a significant effect on the specificity of a diagnostic test. Ideally, this composition should be as similar as possible to the patients routinely tested in clinical practice. Consequently, individuals in whom RA was suspected and then excluded represent a more suitable control group than serological cohorts.

Nevertheless, concerns about the specificity as well as challenges in standardizing and validating a complex immunoassay that uses Ca-FCS is prompting other approaches to the detection of anti-CarP antibodies using immunoassays based on more clearly defined molecular targets such as alpha- 1 antitrypsin ${ }^{6}$, fibrinogen ${ }^{1}$, enolase ${ }^{7}$, or vimentin-derived peptides ${ }^{8}$. To verify the clinical utility of antibodies directed to these molecularly defined CarP targets, studies of larger cohorts will be required. A desirable outcome could be that anti-CarP antibodies that bind defined molecular targets show similar clinical associations such as erosive joint disease, while yielding higher disease specificity.

We acknowledge that measuring anti-CarP antibodies by a conventional Ca-FCS-based anti-CarP ELISA might have limited diagnostic utility by itself ${ }^{4}$. However, as demonstrated, anti-CarP antibodies in combination with $\mathrm{RF}$ and ACPA significantly increase the diagnostic power for the diagnosis of RA (Figure 1$)^{4,9}$. This was also confirmed by Nakabo, et al, who reported that anti-CarP antibodies do not necessarily overlap with ACPA in non-RA patients, which clearly indicates the utility of combining test results. In the event that data on $\mathrm{RF}$ are available for the cohorts, we encourage the authors to calculate and present the OR and Venn diagrams using double and triple positivity, as done by others ${ }^{4,9}$. This is of particular importance because of the attempt to identify patients with RA as early as possible, ideally in the preclinical phase of the disease ${ }^{10}$.

MICHAEL MAHLER, PhD, Inova Diagnostics Inc., San Diego, California, USA; MARVIN J. FRITZLER, MD, PhD, Department of Medicine, Cumming School of Medicine, University of Calgary, Calgary, Alberta, Canada. Address correspondence to Dr. M. Mahler, Inova Diagnostics, 9900 Old Grove Road, San Diego, California 32131-1638, USA.

E-mail: mmahler@inovadx.com or m.mahler.job@web.de.

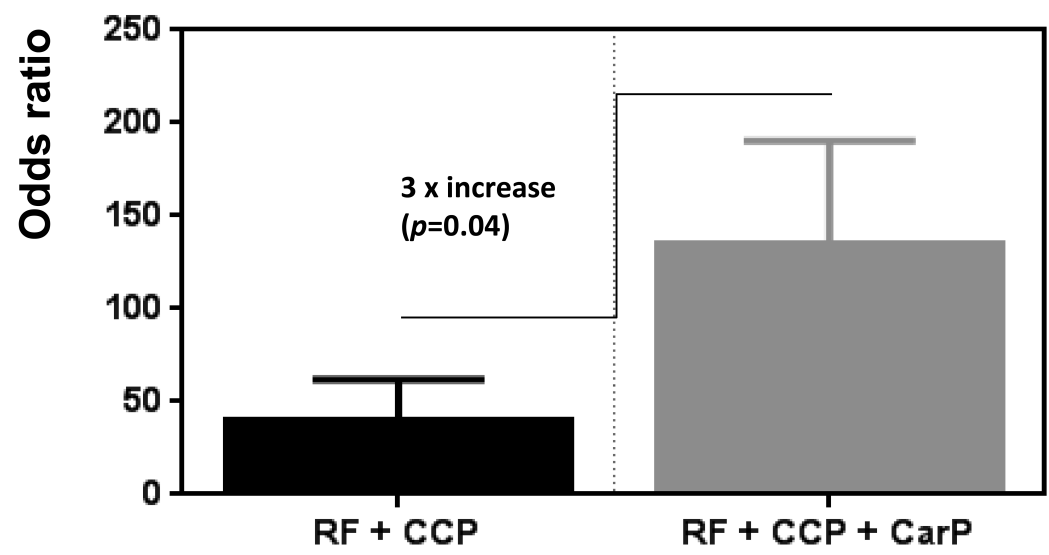

Figure 1. OR for rheumatoid arthritis (RA) for rheumatoid factor (RF) and anticitrullinated protein/peptide antibodies (ACPA) with and without anticarbamylated protein (anti-CarP) antibodies. Adding anti-CarP antibodies to the combination of RF and ACPA (as used in the classification criteria) increased the OR 3-fold from 36.7 to $112.2(\mathrm{p}=0.04)$. Data derived from Shi, et $a l^{4} .95 \% \mathrm{CI}$ are used as error bars. CCP: cyclic citrullinated peptide. 
Dr. Mahler is listed among inventors on a patent application on the detection of anti-CarP antibodies in RA. Dr. Fritzler is a consultant and has received honoraria from Inova Diagnostics Inc. and gifts in kind from Euroimmun GmbH.

\section{REFERENCES}

1. Trouw LA, Mahler M. Closing the serological gap: promising novel biomarkers for the early diagnosis of rheumatoid arthritis. Autoimmun Rev 2012;12:318-22.

2. Shi J, van Veelen PA, Mahler M, Janssen GM, Drijfhout JW, Huizinga TW, et al. Carbamylation and antibodies against carbamylated proteins in autoimmunity and other pathologies. Autoimmun Rev 2014;13:225-30.

3. Li L, Deng C, Chen S, Zhang S, Wu Z, Hu C, et al. Meta-analysis: diagnostic accuracy of anti-carbamylated protein antibody for rheumatoid arthritis. PLoS One 2016;11:e0159000.

4. Shi J, van Steenbergen HW, van Nies JA, Levarht EW, Huizinga TW, van der Helm-van Mil AH, et al. The specificity of anti-carbamylated protein antibodies for rheumatoid arthritis in a setting of early arthritis. Arthritis Res Ther 2015;17:339.

5. Nakabo S, Yoshifuji H, Hashimoto M, Imura Y, Nakashima R, Murakami K, et al. Anti-carbamylated protein antibodies are detectable in various connective tissue diseases. J Rheumatol 2017;44:1384-8.
6. Verheul MK, Yee A, Seaman A, Janssen GM, van Veelen PA, Drijfhout JW, et al. Identification of carbamylated alpha 1 anti-trypsin (A1AT) as an antigenic target of anti-CarP antibodies in patients with rheumatoid arthritis. J Autoimmun 2017;80:77-84.

7. Reed E, Jiang X, Kharlamova N, Ytterberg AJ, Catrina AI, Israelsson L, et al. Antibodies to carbamylated alpha-enolase epitopes in rheumatoid arthritis also bind citrullinated epitopes and are largely indistinct from anti-citrullinated protein antibodies. Arthritis Res Ther 2016;18:96.

8. Juarez M, Bang H, Hammar F, Reimer U, Dyke B, Sahbudin I, et al. Identification of novel antiacetylated vimentin antibodies in patients with early inflammatory arthritis. Ann Rheum Dis 2016; 75:1099-107.

9. Koppejan H, Trouw LA, Sokolove J, Lahey LJ, Huizinga TJ, Smolik IA, et al. Role of anti-carbamylated protein antibodies compared to anti-citrullinated protein antibodies in indigenous North Americans with rheumatoid arthritis, their first-degree relatives, and healthy controls. Arthritis Rheumatol 2016; 68:2090-8.

10. Mahler M. Population-based screening for ACPAs: a step in the pathway to the prevention of rheumatoid arthritis? Ann Rheum Dis 2017;76:e42.

J Rheumatol 2018;45:3; doi:10.3899/jrheum.170677 